\title{
DATA MINING DALAM PENGELOMPOKAN JENIS DAN JUMLAH PEMBAGIAN ZAKAT DENGAN MENGGUNAKAN METODE CLUSTERING K-MEANS (STUDI KASUS: BADAN AMIL ZAKAT KOTA BENGKULU)
}

\author{
Prahasti \\ Program Studi Teknik Informatika Fakultas Ilmu Komputer Universitas Dehasen Bengkulu \\ Jl. Meranti Raya No. 32 Kota Bengkulu. 38228 Telp.(0736) 22027, 265957 Fax.(0736) 341139 \\ prahasti.mona82@gmail.com
}

\begin{abstract}
ABSTRAK - Penelitian ini menerapkan data mining dengan dalam pengelompokan jenis dan penerima zakat. Penerapannya dilakukan dengan algoritma k-means clustering dimana data yang akan diinputkan dikelompokkan berdasarkan pendidikan dan jenis pekerjaan dalam pembagian zakat. Kemudian dibentuk cluster dengan menggunakan nilai centroid untuk menentukan titik pusat terdekat jarak antar data. Dalam algoritma k-means clustering pengolahan data dihentikan dalam hitungan iterasi data tidak mengalami perubahan (data tetap) dari data yang telah dikelompokkan tersebut. Pengujiannya dilakukan dengan menggunakan perangkat lunak RapidMiner percobaan yang dilakukan dengan metode k-means clustering yang terdiri dari unit masukan, unit pengolahan data dan unit keluarannya, k-means clustering pengelompokan data 12-1-1, 1-2-1-2 dan 3-4-3-4. Hasil yang didapat dari pengujian tersebut adalah pengelompokan pembagian zakat dengan setiap cluster tidak sama. Hasil pengujiannya ditampilkan dalam bentuk grafik slatter.
\end{abstract}

Kata Kunci : Data Mining, K-Means Clusttering, Zakat

ABSTRACT - This research applies data mining with in grouping type and receiver of zakat. The application is done by k-means clustering algorithm where the data to be input is grouped based on education and the type of work in the distribution of zakat. Then formed cluster by using centroid value to determine the nearest center point of distance between data. In the k-means clustering algorithm the data processing is stopped in a matter of data iteration has not changed (fixed data) from the data that has been grouped. Testing is done by using RapidMiner software experiments conducted with $k$-means clustering method consisting of input units, data processing units and output units, k-means clustering grouping data 1-2-1-1, 1-2-1-2 and 3-4-3-4. The results obtained from the test is the grouping of zalcat sharing with each cluster is not the same. Test results are displayed in the form of slatter graphs.

Keywords: Data Mining, K-Means Clusttering, Zakat

\section{PENDAHULUAN}

Setiap lembaga mempunyai system operasional yang setia transaksi kegiatan operasinya selalu dicatat dan didokumentasikan. Setiap transaksi sangat berguna bagi lembaga tersebut untuk segala keperluan.

Data mining merupakan salah satu cabang ilmu komputer yang relative baru. Dimana data mining mengekstraksi informasi atau pola yang penting atau menarik dari data yang ada di database yang besar.

Data mining diterapkan di banyak bidang seperti dikemukakan oleh Suprihatin (2011) menyatakan bahwa teknik clustering $k$-means digunakan untuk menentukan nilai huruf ujian akhir pada Universitas Ahmad Dahlan (UAD). Tutik (2014) mengelompokkan surat-surat dalam Al-Qur'an berdasarkan ayat, jumlah ruku' dan lama membaca surat dengan menggunakan algoritma clustering k-means 
untuk menemukan hasil yang optimal. Deka (2014) menerangkan bahwa teknik clustering $k$ means digunakan untuk mengelompokkan judul buku sesuai dengan kategorinya sehingga memudahkan pustakawan dalam pengelompokan peletakan buku dan merancang strategi dalam meningkatkan minat baca mahasiswa pada Universitas Islam Indonesia. Andika (2008) mengemukakan bahwa algoritma $k$-means clustering dapat diimplementasikan dengan metode perangkat lunak untuk verifikasi citra sidik jari poin minutiae. Tahta (2012) menjelaskan tentang gabungan metode single linkage clustering dan k-means dalam menyelesaikan problem kerja praktek Jurusan Teknik Industri ITS sehingga memberikan hasil cluster yang lebih baik dengan parameter uji cluster variance dan metode silhouette coefisien.

Penelitian menerapkan data mining untuk mengolah data jenis dan jumlah pembagian zakat pada Badan Amil Zakat Kota Bengkulu. Zakat yang dibayarkan merupakan salah satu tuntunan bagi setiap umat muslim menurut syariat Islam, untuk mengolah jenis dan jumlah pembagian zakat, dibutuhkan sebuah metode yang bisa digunakan untuk menggali informasi tersembunyi dari data tersebut. Metode tersebut dilakukan dengan menggunakan metode data mining.

Penelitian dilakukan untuk menganalisa data mining dengan metode clustering $\quad k$-Means yang kemudian diterjemahkan dalam sebuah perangkat lunak yang digunakan untuk mengelompokkan jenis zakat dan pembagian zakat berdasarkan data yang dilakukan sehingga didapat kelompok-kelompok jenis dan jumlah pembagian zakat menurut syariat Islam khususnya bagi mereka (pemilik harta) yang telah memenuhi persyaratan syar'i (nishab dan haul) sebagai wajib zakat (muzzaki).

\section{LANDASAN TEORI}

A. Knowledge Discovery in Database (KKD) Knowledge Discovery in Database (KKD) merupakan kegiatan yang meliputi pengumpulan, pemakaian data historis untuk menemukan keteraturan, pola atau hubungan dalam set data berukuran besar (Deka, 2014)

\section{B. Data Mining}

Data mining adalah proses yang menggunakan teknik statistic, matematika, kecerdasan buatan dan machine learing untuk mengektraksi dan mengindentifikasi informasi yang bermanfaat dan pengetahuan yang terkait dari database yang besar (Tacbir Hendro Pudjiantoro, 2011). Menurut Santosa data mining adalah suatu metode pengolahan data untuk menemukan pola yang tersembunyi dari data tersebut. Hasil dari pengolahan data dengan metode data mining ini dapat digunakan untuk mengambil keputusan dimasa depan. Data mining ini juga dikenal dengan istilah pattern recognition (Johan Oscar Ong, 2013).

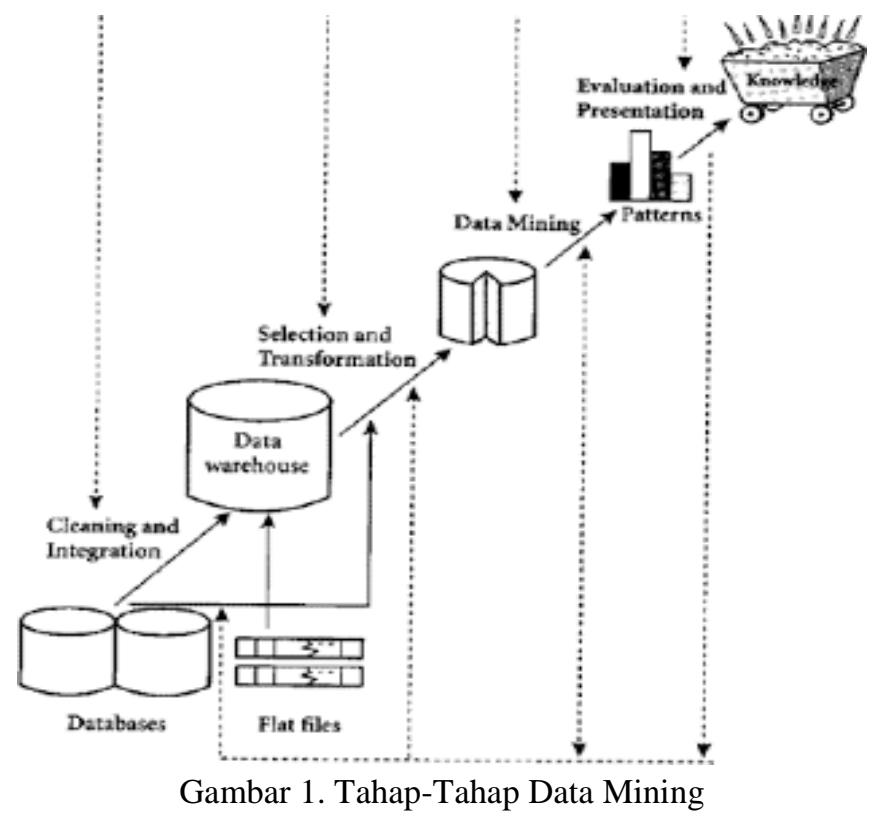


C. K-Means Clustering

Metode $k$-means clustering merupakan metode pengelompokan partitioned clustering. Metode $k$-means mengelompokkan dokumen didasarkan pada jarak terdekat dengan centroid. $K$-means merupakan metode pengelompokan yang sederhana dan dapat digunakan dengan mudah. Tetapi pada jenis data tertentu, K-means tidak dapat memberikan segmentasi data dengan baik, sehingga kelompok yang terbentuk tidak murni data yang sama (Rendi Handoyo, 2014).

Pengelompokan data dengan metode KMeans ini secara umum dilakukan dengan algoritma.

1. Tentukan jumlah kelompok.

2. Alokasikan data ke dalam kelompok secara acak.

3. Hitung pusat kelompok (centroid/ratarata) dari data yang ada di masingmasing kelompok.

4. Alokasikan masing-masing data ke centroid/rata-rata terdekat.

5. Kembali ke langkah c, apabila masih ada data yang berpindah kelompok, atau apabila ada perubahan nilai centroid diatas nilai ambang yang ditentukan, atau apabila perubahan nilai pada fungsi objektif yang digunakan masih di atas nilai ambang yang ditentukan

\section{ZAKAT}

Zakat adalah salah satu rukun Islam yang memiliki dimensi ibadah dan muamalah sekaligus. Menunaikan zakat adalah kewajiban ibadah yang merupakan konsekwensi ketaatan kepada perintah Allah SWT, dan pemanfaatannya dapat membantu menyelesaikan permasalahan ekonomi (muamalah) yang dihadapi oleh masyarakat (Gamsir Bachmid, 2012).

Syarat-syarat wajib zakat yaitu:

1. Islam : Zakat hanya diwajibkan bagi orang Islam saja.

2. Merdeka: hamba sahaya tidak wajib mengeluarkan zakat kecuali zakat fitrah, sedangkan tuannya wajib mengeluarkannya.

3. Milik sepenuhnya: harta yang akan dizakati hendaknya miliki sepenuhnya orang yang beragama Islam dan harus merdeka.

4. Cukup Haul: maksudnya harta tersebut dimiliki genap setahun selama 354 hari menurut tanggal hijriah atau 365 hai menurut tanggalan Masehi.

5. Cukup Nisab: nisab adalah nilai minimal sesuatu harta yang wajib dikeluarkan zakatnya.

\section{ANALISA DAN PERANCANGAN SISTEM}

Tabel 1. Sampel Data Warga Penerima Zakat

\begin{tabular}{|c|l|l|l|c|}
\hline No & Nama Warga & $\begin{array}{c}\text { Pendidikan } \\
\text { Tertinggi }\end{array}$ & Pekerjaan & $\begin{array}{c}\text { Penghasilan/Bulan } \\
\text { (Ribuan) }\end{array}$ \\
\hline 1 & Aminudin & SD & Buruh & 700 \\
\hline 2 & Awaludin & SD & Buruh & 750 \\
\hline 3 & Yuhir Ajoyo & SMP & Nelayan & 550 \\
\hline 4 & Iskandar & SD & Buruh & 750 \\
\hline 5 & Yanuar & SMA & Nelayan & 650 \\
\hline 6 & Azman & SMP & Pedagang & 900 \\
\hline 7 & Heri Gunawan & SMA & Pedagang & 900 \\
\hline 8 & Harta Gunawan & SMA & Nelayan & 550 \\
\hline 9 & Apriyandi & SMP & Buruh & 740 \\
\hline 10 & Hermawansyah & SMP & Nelayan & 580 \\
\hline 11 & Sahirman & SMA & Petani & 840 \\
\hline 12 & Ninsarman & Tidak Sekolah & Petani & 800 \\
\hline 13 & Sucipto & SMP & Nelayan & 560 \\
\hline 14 & Mulyanto & SMA & Pedagang & 900 \\
\hline 15 & Mulyadi & SD & Nelayan & 560 \\
\hline 16 & Ansori Saleh & SMP & Buruh & 500 \\
\hline 17 & Zamzami & SMA & Buruh & 700 \\
\hline 18 & Suratno & SMP & Buruh & 700 \\
\hline
\end{tabular}




\begin{tabular}{|c|l|l|l|c|}
\hline No & \multicolumn{1}{|c|}{ Nama Warga } & $\begin{array}{c}\text { Pendidikan } \\
\text { Tertinggi }\end{array}$ & \multicolumn{1}{|c|}{ Pekerjaan } & $\begin{array}{c}\text { Penghasilan/Bulan } \\
\text { (Ribuan) }\end{array}$ \\
\hline 19 & Kustomo & SMP & Buruh & 750 \\
\hline 20 & $\begin{array}{l}\text { Rohim } \\
\text { Nopriandi }\end{array}$ & SMA & Petani & 850 \\
\hline 21 & Sugianto & SMA & Pedagang & 950 \\
\hline 22 & Aliwar & SMP & Petani & 840 \\
\hline 23 & Pahrorozi & SMP & Petani & 800 \\
\hline 24 & Supriyanto & Tidak Sekolah & Petani & 800 \\
\hline 25 & Kurniawan & SD & Nelayan & 550 \\
\hline
\end{tabular}

A. Tahap Tranformasi Data

Dengan menggunakan metode k-means clustering, dilakukan transsformasi data yang berjenis data nominal yaitu pekerjaan dan pendidikan. Data berjenis nominal tersebut diinisialisasikan ke dalam bentuk angka melalui beberapa langkah agar dapat diolah dengan menggunakan metode algoritma k-means clustering. Hasil masing-masing inisialisasi sampel data:

Tabel 2. Inisialisasi Data Pendidikan Tertinggi

\begin{tabular}{|l|c|c|}
\hline \multicolumn{1}{|c|}{ Pendidikan } & Frekuensi & Inisilisasi \\
\hline SMP & 10 & 1 \\
\hline SMA & 8 & 2 \\
\hline SD & 5 & 3 \\
\hline $\begin{array}{l}\text { Tidak } \\
\text { Sekolah }\end{array}$ & 2 & 4 \\
\hline
\end{tabular}

Tabel 3. Inisialisasi Data Pekerjaan

\begin{tabular}{|l|l|l|}
\hline Pekerjaan & Frekuensi & Inisilisasi \\
\hline Buruh & 8 & 1 \\
\hline Nelayan & 7 & 2 \\
\hline Petani & 6 & 3 \\
\hline Pedagang & 4 & 4 \\
\hline
\end{tabular}

Tabel 4. Hasil Penghitungan Jarak Setiap Data Untuk Masing-Masing Cluster (Iterasi 1)

\begin{tabular}{|c|c|c|c|c|c|c|c|c|c|}
\hline \multirow{2}{*}{ No } & \multirow{2}{*}{ Nama Warga } & \multirow{2}{*}{$\begin{array}{l}\text { Pendi } \\
\text { dikan }\end{array}$} & \multirow{2}{*}{$\begin{array}{c}\text { Pek } \\
\text { erja } \\
\text { an }\end{array}$} & \multirow{2}{*}{$\begin{array}{c}\text { Pengha } \\
\text { silan }\end{array}$} & \multicolumn{3}{|c|}{ Jarak Ke centroid } & \multirow[t]{2}{*}{$\begin{array}{c}\text { Jarak } \\
\text { Terdekat }\end{array}$} & \multirow[t]{2}{*}{$\begin{array}{c}\text { Cluste } \\
\mathrm{r}\end{array}$} \\
\hline & & & & & $\mathrm{C} 0$ & $\mathrm{C} 1$ & $\mathrm{C} 2$ & & \\
\hline 1 & Aminudin & 3 & 1 & 700 & 50.020 & 200.125 & 200.010 & 50.020 & $\mathrm{CO}$ \\
\hline 2 & Awaludin & 3 & 1 & 750 & 100.010 & 150.033 & 250.008 & 100.010 & $\mathrm{CO}$ \\
\hline 3 & Yuhir Ajoyo & 1 & 2 & 550 & 100.005 & 350.007 & 50.010 & 50.010 & $\mathrm{C} 2$ \\
\hline 4 & Iskandar & 3 & 1 & 750 & 100.010 & 150.033 & 250.008 & 100.010 & $\mathrm{CO}$ \\
\hline 5 & Yanuar & 2 & 2 & 650 & 0 & 250.008 & 150.007 & 0 & $\mathrm{CO}$ \\
\hline 6 & Azman & 1 & 4 & 900 & 250.010 & 1 & 400.011 & 1 & $\mathrm{C} 1$ \\
\hline 7 & Heri Gunawan & 2 & 4 & 900 & 250.008 & 0 & 400.012 & 0 & $\mathrm{C} 1$ \\
\hline 8 & $\begin{array}{l}\text { Harta } \\
\text { Gunawan }\end{array}$ & 2 & 2 & 550 & 100 & 350.006 & 50.020 & 50.020 & $\mathrm{C} 2$ \\
\hline 9 & Apriyandi & 1 & 1 & 740 & 90.011 & 160.031 & 240 & 90.011 & $\mathrm{CO}$ \\
\hline 10 & $\begin{array}{l}\text { Hermawansya } \\
\mathrm{h}\end{array}$ & 1 & 2 & 580 & 70.007 & 320.008 & 80.006 & 70.007 & $\mathrm{C} 2$ \\
\hline 11 & Sahirman & 2 & 3 & 840 & 190.003 & 60.00 & 340.007 & 60.00 & $\mathrm{C} 1$ \\
\hline 12 & Ninsarman & 4 & 3 & 800 & 150.017 & 100.025 & 300.022 & 100.025 & $\mathrm{C} 1$ \\
\hline
\end{tabular}




\begin{tabular}{|c|c|c|c|c|c|c|c|c|c|}
\hline \multirow{2}{*}{ No } & \multirow{2}{*}{ Nama Warga } & \multirow{2}{*}{$\begin{array}{l}\text { Pendi } \\
\text { dikan }\end{array}$} & \multirow{2}{*}{$\begin{array}{c}\text { Pek } \\
\text { erja } \\
\text { an }\end{array}$} & \multirow{2}{*}{$\begin{array}{c}\text { Pengha } \\
\text { silan }\end{array}$} & \multicolumn{3}{|c|}{ Jarak Ke centroid } & \multirow{2}{*}{$\begin{array}{c}\text { Jarak } \\
\text { Terdekat }\end{array}$} & \multirow{2}{*}{$\begin{array}{c}\text { Cluste } \\
\mathrm{r}\end{array}$} \\
\hline & & & & & $\mathrm{C} 0$ & $\mathrm{C} 1$ & $\mathrm{C} 2$ & & \\
\hline 13 & Sucipto & 1 & 2 & 560 & 90.006 & 340.007 & 60.008 & 60.008 & $\mathrm{C} 2$ \\
\hline 14 & Mulyanto & 2 & 4 & 900 & 250.008 & 0 & 400.012 & 0 & $\mathrm{C} 1$ \\
\hline 15 & Mulyadi & 3 & 2 & 560 & 90.006 & 340.007 & 60.042 & 60.042 & $\mathrm{C} 2$ \\
\hline 16 & Ansori Saleh & 1 & 1 & 500 & 150.007 & 400.012 & 0 & 0 & $\mathrm{C} 2$ \\
\hline 17 & Zamzami & 2 & 1 & 700 & 50.010 & 200.022 & 200.002 & 50.010 & $\mathrm{C} 0$ \\
\hline 18 & Suratno & 1 & 1 & 700 & 50.020 & 200.025 & 200 & 50.020 & $\mathrm{C} 0$ \\
\hline 19 & Kustomo & 1 & 1 & 750 & 100.010 & 150.033 & 250 & 100.010 & $\mathrm{C} 1$ \\
\hline 20 & $\begin{array}{l}\text { Rohim } \\
\text { Nopriandi }\end{array}$ & 2 & 3 & 850 & 200.002 & 50.010 & 350.007 & 50.010 & $\mathrm{C} 1$ \\
\hline 21 & Sugianto & 2 & 4 & 950 & 300.007 & 50 & 450.011 & 50 & $\mathrm{C} 1$ \\
\hline 22 & Aliwar & 1 & 3 & 840 & 190.005 & 60.017 & 340.006 & 60.017 & $\mathrm{C} 1$ \\
\hline 23 & Pahrorozi & 1 & 3 & 800 & 150.007 & 100.010 & 300.007 & 100.010 & $\mathrm{C} 1$ \\
\hline 24 & Supriyanto & 4 & 3 & 800 & 150.017 & 100.025 & 300.022 & 100.025 & $\mathrm{C} 1$ \\
\hline 25 & Kurniawan & 3 & 1 & 550 & 100 & 350.007 & 50.050 & 50.050 & $\mathrm{C} 2$ \\
\hline
\end{tabular}

Tabel 5. Hasil Penghitungan Jarak Setiap Data Untuk Masing-Masing Cluster (Iterasi 2)

\begin{tabular}{|c|c|c|c|c|c|c|c|c|c|}
\hline \multirow{2}{*}{ No } & \multirow{2}{*}{ Nama Warga } & \multirow{2}{*}{$\begin{array}{l}\text { Pendi } \\
\text { dikan }\end{array}$} & \multirow{2}{*}{$\begin{array}{c}\text { Pek } \\
\text { erja } \\
\text { an }\end{array}$} & \multirow{2}{*}{$\begin{array}{c}\text { Pengha } \\
\text { silan }\end{array}$} & \multicolumn{3}{|c|}{ Jarak Ke centroid } & \multirow{2}{*}{$\begin{array}{c}\text { Jarak } \\
\text { Terdekat }\end{array}$} & \multirow[t]{2}{*}{ Cluster } \\
\hline & & & & & $\mathrm{C} 0$ & $\mathrm{C} 1$ & $\mathrm{C} 2$ & & \\
\hline 1 & Aminudin & 3 & 1 & 700 & 2.494 & 153.019 & 155.007 & 2.494 & $\mathrm{C} 0$ \\
\hline 2 & Awaludin & 3 & 1 & 750 & 47.791 & 103.028 & 205.005 & 47.791 & $\mathrm{C} 0$ \\
\hline 3 & Yuhir Ajoyo & 1 & 2 & 550 & 152.227 & 303.004 & 5.072 & 5.072 & $\mathrm{C} 2$ \\
\hline 4 & Iskandar & 3 & 1 & 750 & 47.791 & 103.028 & 205.005 & 47.791 & $\mathrm{C} 0$ \\
\hline 5 & Yanuar & 2 & 2 & 650 & 52.228 & 203.004 & 105 & 52.228 & $\mathrm{C} 0$ \\
\hline 6 & Azman & 1 & 4 & 900 & 197.799 & 47.017 & 355.008 & 42.017 & $\mathrm{C} 1$ \\
\hline 7 & Heri Gunawan & 2 & 4 & 900 & 197.797 & 47.007 & 355.007 & 47.007 & $\mathrm{C} 1$ \\
\hline 8 & $\begin{array}{l}\text { Harta } \\
\text { Gunawan }\end{array}$ & 2 & 2 & 550 & 152.224 & 303.002 & 5.006 & 5.006 & $\mathrm{C} 2$ \\
\hline 9 & Apriyandi & 1 & 1 & 740 & 37.789 & 113.026 & 195.004 & 37.789 & $\mathrm{C} 0$ \\
\hline 10 & $\begin{array}{l}\text { Hermawansya } \\
\mathrm{h}\end{array}$ & 1 & 2 & 580 & 122.228 & 273.004 & 35.010 & 35.010 & $\mathrm{C} 2$ \\
\hline 11 & Sahirman & 2 & 3 & 840 & 137.799 & 13.002 & 295.002 & 13.003 & $\mathrm{C} 1$ \\
\hline 12 & Ninsarman & 4 & 3 & 800 & 97.817 & 53.038 & 255.012 & 58.032 & $\mathrm{C} 1$ \\
\hline 13 & Sucipto & 1 & 2 & 560 & 142.227 & 293.004 & 15.024 & 15.024 & $\mathrm{C} 2$ \\
\hline 14 & Mulyanto & 2 & 4 & 900 & 197.797 & 47.007 & 355.007 & 42.007 & $\mathrm{C} 1$ \\
\hline 15 & Mulyadi & 3 & 2 & 560 & 142.229 & 293.004 & 15.046 & 15.046 & $\mathrm{C} 2$ \\
\hline 16 & Ansori Saleh & 1 & 1 & 500 & 202.224 & 353.008 & 45.015 & 45.015 & $\mathrm{C} 2$ \\
\hline 17 & Zamzami & 2 & 1 & 700 & 2.236 & 153.016 & 155.002 & 2.236 & $\mathrm{C} 0$ \\
\hline 18 & Suratno & 1 & 1 & 700 & 2.404 & 153.019 & 155.004 & 2.404 & $\mathrm{C} 0$ \\
\hline 19 & Kustomo & 1 & 1 & 750 & 47.787 & 103.028 & 205.003 & 47.787 & $\mathrm{C} 1$ \\
\hline 20 & $\begin{array}{l}\text { Rohim } \\
\text { Nopriandi }\end{array}$ & 2 & 3 & 850 & 147.789 & 3.007 & 305.002 & 3.007 & $\mathrm{C} 1$ \\
\hline 21 & Sugianto & 2 & 4 & 950 & 247.793 & 97.003 & 405.006 & 97.003 & $\mathrm{C} 1$ \\
\hline 22 & Aliwar & 1 & 3 & 840 & 137.792 & 13.040 & 295.003 & 13.040 & $\mathrm{C} 1$ \\
\hline 23 & Pahrorozi & 1 & 3 & 800 & 97.798 & 53.010 & 255.004 & 53.010 & $\mathrm{C} 1$ \\
\hline 24 & Supriyanto & 4 & 3 & 800 & 97.817 & 53.038 & 255.012 & 53.038 & $\mathrm{C} 1$ \\
\hline 25 & Kurniawan & 3 & 1 & 550 & 152.228 & 303.004 & 5.137 & 5.137 & $\mathrm{C} 2$ \\
\hline
\end{tabular}


Tabel 6. Hasil Penghitungan Jarak Setiap Data Untuk Masing-Masing Cluster (Iterasi 1)

\begin{tabular}{|c|c|c|c|c|c|c|c|c|c|}
\hline \multirow{2}{*}{ No } & \multirow{2}{*}{ Nama Warga } & \multirow{2}{*}{$\begin{array}{l}\text { Pendi } \\
\text { dikan }\end{array}$} & \multirow{2}{*}{$\begin{array}{c}\text { Pek } \\
\text { erja } \\
\text { an }\end{array}$} & \multirow{2}{*}{$\begin{array}{l}\text { Pengha } \\
\text { silan }\end{array}$} & \multicolumn{3}{|c|}{ Jarak Ke centroid } & \multirow[t]{2}{*}{$\begin{array}{c}\text { Jarak } \\
\text { Terdekat }\end{array}$} & \multirow[t]{2}{*}{ Cluster } \\
\hline & & & & & $\mathrm{CO}$ & $\mathrm{C} 1$ & $\mathrm{C} 2$ & & \\
\hline 1 & Aminudin & 3 & 1 & 700 & 17.529 & 158.021 & 150.008 & 17.529 & $\mathrm{CO}$ \\
\hline 2 & Awaludin & 3 & 1 & 750 & 32.516 & 108.030 & 200.006 & 32.516 & $\mathrm{CO}$ \\
\hline 3 & Yuhir Ajoyo & 1 & 2 & 550 & 167.505 & 308.005 & 0.728 & 0.728 & $\mathrm{C} 2$ \\
\hline 4 & Iskandar & 3 & 1 & 750 & 32.516 & 108.030 & 200.006 & 32.516 & $\mathrm{CO}$ \\
\hline 5 & Yanuar & 2 & 2 & 650 & 67.506 & 208.005 & 100.001 & 67.506 & $\mathrm{CO}$ \\
\hline 6 & Azman & 1 & 4 & 900 & 182.525 & 42.019 & 350.007 & 42.019 & $\mathrm{C} 1$ \\
\hline 7 & Heri Gunawan & 2 & 4 & 900 & 182.523 & 42.004 & 350.007 & 42.004 & $\mathrm{C} 1$ \\
\hline 8 & $\begin{array}{l}\text { Harta } \\
\text { Gunawan }\end{array}$ & 2 & 2 & 550 & 167.502 & 308.003 & 0.319 & 0.319 & $\mathrm{C} 2$ \\
\hline 9 & Apriyandi & 1 & 1 & 740 & 22.523 & 118.030 & 190.003 & 22.523 & $\mathrm{CO}$ \\
\hline 10 & $\begin{array}{l}\text { Hermawansya } \\
\text { h }\end{array}$ & 1 & 2 & 580 & 137.506 & 278.006 & 30.009 & 30.009 & $\mathrm{C} 2$ \\
\hline 11 & Sahirman & 2 & 3 & 840 & 122.514 & 18.005 & 290.002 & 18.005 & $\mathrm{C} 1$ \\
\hline 12 & Ninsarman & 4 & 3 & 800 & 82.546 & 58.032 & 250.013 & 58.032 & $\mathrm{C} 1$ \\
\hline 13 & Sucipto & 1 & 2 & 560 & 157.506 & 298.005 & 10.026 & 10.026 & $\mathrm{C} 2$ \\
\hline 14 & Mulyanto & 2 & 4 & 900 & 182.523 & 42.004 & 350.007 & 42.004 & $\mathrm{C} 1$ \\
\hline 15 & Mulyadi & 3 & 2 & 560 & 157.506 & 298.005 & 10.083 & 10.083 & $\mathrm{C} 2$ \\
\hline 16 & Ansori Saleh & 1 & 1 & 500 & 217.502 & 358.010 & 50.012 & 50.012 & $\mathrm{C} 2$ \\
\hline 17 & Zamzami & 2 & 1 & 700 & 17.500 & 158.018 & 150.003 & 17.500 & $\mathrm{CO}$ \\
\hline 18 & Suratno & 1 & 1 & 700 & 17.529 & 158.022 & 150.004 & 17.529 & $\mathrm{CO}$ \\
\hline 19 & Kustomo & 1 & 1 & 750 & 32.526 & 108.032 & 200.003 & 32.516 & $\mathrm{C} 1$ \\
\hline 20 & $\begin{array}{l}\text { Rohim } \\
\text { Nopriandi }\end{array}$ & 2 & 3 & 850 & 132.513 & 8.011 & 300.002 & 8.011 & $\mathrm{C} 1$ \\
\hline 21 & Sugianto & 2 & 4 & 950 & 232.518 & 92.002 & 400.006 & 92.002 & $\mathrm{C} 1$ \\
\hline 22 & Aliwar & 1 & 3 & 840 & 122.528 & 18.038 & 290.003 & 18.038 & $\mathrm{C} 1$ \\
\hline 23 & Pahrorozi & 1 & 3 & 800 & 82.527 & 58.012 & 100.001 & 58.012 & $\mathrm{C} 1$ \\
\hline 24 & Supriyanto & 4 & 3 & 800 & 82.546 & 58.032 & 250.013 & 58.032 & $\mathrm{C} 1$ \\
\hline 25 & Kurniawan & 3 & 1 & 550 & 167.505 & 308.004 & 1.294 & 1.294 & $\mathrm{C} 2$ \\
\hline
\end{tabular}

3. Proses perhitungan tela dilakukan dan pada iterasi ke-2 dan ke -3 ternyata posisi cluster tidak mengalami perubahan disamping itu, tidak adanya data lagi yang berpindah dari satu cluster ke cluster yang lain. Untuk itu proses iterasi dihentikan dan hasil dari perhitungan diperoleh sebanyak 3 cluster dengan 3 iterasi.

4. Disamping itu, berdasarkan data perhitungan iterasi diperoleh hasil pengelompokan data sebagai berikut:

Tabel 7 Hasil Pengelompokan

\begin{tabular}{|c|c|c|}
\hline Kel & Anggota Kelompok & $\begin{array}{c}\text { Jumlah } \\
\text { Anggota }\end{array}$ \\
\hline 0 & {$[1,2,4,5,9,17,18,19]$} & 8 anggota \\
\hline 1 & {$[6,7,11,12,14,20,21$,} & 10 anggota \\
& $22,23,24]$ & \\
\hline 2 & {$[3,8,10,13,15,16,25]$} & 7 anggota \\
\hline
\end{tabular}

Dari proses clustering atau pengelompokan diatas maka dihasilkan pengelompokan berdasarkan kedekatan jarak antar titik pusat dengan data warga dari setiap atributnya. Adapun hasil dari penelitian seperti terlihat pada table dibawah ini:

Tabel 8. Hasil Penelitian

\begin{tabular}{|c|c|c|}
\hline \multirow[b]{2}{*}{ Cluster } & \multicolumn{2}{|c|}{ Hasil Penelitian } \\
\hline & $\begin{array}{c}\text { Centroid } \\
\text { Akhir }\end{array}$ & Anggota \\
\hline $\begin{array}{l}\text { Clustte } \\
\text { r } 0\end{array}$ & $\begin{array}{c}2,1.125, \\
717.5\end{array}$ & $\begin{array}{l}\text { Jumlah anggota }=8 \\
\text { orang. } \\
\text { Terdiri dari: } \\
\text { 1. Pendidikan SD } \\
\text { dan Pekerjaan } \\
\text { Buruh sebanyak } \\
3 \text { warga. } \\
\text { a. Anggota. } \\
\text { b. Aminudin } \\
\text { c. Awwaludin } \\
\text { d. Iskandar }\end{array}$ \\
\hline
\end{tabular}




\begin{tabular}{|c|c|c|}
\hline \multirow[b]{2}{*}{ Cluster } & \multicolumn{2}{|c|}{ Hasil Penelitian } \\
\hline & $\begin{array}{c}\text { Centroid } \\
\text { Akhir }\end{array}$ & Anggota \\
\hline & & $\begin{array}{l}\text { 2. Pendidikan } \\
\text { SMP dan } \\
\text { Pekerjaan } \\
\text { Buruh sebanyak } \\
3 \text { warga. } \\
\text { Anggota: } \\
\text { a. Apiyadi } \\
\text { b. Suratno } \\
\text { c. Kustomo } \\
\text { 3. Pendidikan } \\
\text { SMA dan } \\
\text { Pekerjaan } \\
\text { Buruh sebanyak } \\
\text { 1 warga } \\
\text { Anggota: } \\
\text { a. Zamzami. } \\
\text { Pendidikan } \\
\text { SMA dan } \\
\text { pekerjaan dan } \\
\text { Nelayan } \\
\text { sebanyak } 1 \\
\text { warga } \\
\text { Anggota: } \\
\text { a. Yanuar }\end{array}$ \\
\hline
\end{tabular}

\section{PENUTUP}

Kesimpulan

1. Menentukan cluster dari masing-masing setiap data sangat penting dilakukan sehingga didapat suatu inisiasi data dari nomial kedalam data numeric.

2. Penerapan clusteing k-means mampu menghasilkan pengelompokan jenis dan pembagian zakat menggunakan data riil dan baik digunakan sebagai cara untuk pengelompokan jenis dan penerima zakat.

3. Clustering K-means mampu memberikan hasil yang baik dan dapat digunakan untuk pengolahan data pengelompokan jenis dan pembagian zakat pada pada tahun-tahun berikutnya.

4. Hasil pengujian yang didapat dapat memberikan hasil yang baik sehingga dapat digunakan untuk pengolahan pengelompokan jenis dan pembagian zakat untuk tahun-tahun berikutnya.

Saran

1. Perbaikan prosedur kerja yang berhubungan dengan proses pemasukan data-data transaksi kedalam system basis data pelu mendapat perhatian yang khusus sehingga ketersediaan data padaa saat diperlukan dapat lebih terjamin.

2. Hasil penelitian ini diharapakan dapat digunakan Badan Amil Zakat Kota Bengkulu, sebagai rujukan atau menganalisa untuk lebih meningkatkan akurasi analisa kelayakan menentukan pengelompokan jenis dan pembagian zakat lebih optimal.

3. Melakukan pengembangan dengan menggunakan metode optimasi yang lain atau degnan seleksi fitur untuk ketepatan penyelesaian atribut.

\section{DAFTAR PUSTAKA}

[1] Goldie Gunadi,et.al (2012). "Penerapan Metode Data Mining Market Basket Analysis Terhadap Data Penjualan Produk Buku Dengan Menggunakan Algoritma Apriori dan Frequent Pattern Growth (FpGrowth)" Ed. Jurnal Telematika Mkom Vol 4 No.1

[2] Afrisawati (2013). "Implementasi Data Mining Pemilihan Pelanggan Potensial Menggunakan Algoritma K-Means" Ed. Pelita Informatika Budi Darma, Volume: V No.3.

[3] Gamsir Bachdim (2011) "Perilaku Muzaaki dalam membayar zakat mal (Studi Fenomenologi Pengaki di Kota Kediri” Ed. Jurnal Aplikasi Manajemen Vol.10..

[4] Johan Oscar Ong (2003) "Implementasi Algoritma K-Means Clustering Untuk Menentukan Strategi Marketing Presiden University" Ed. Jurnal Ilmiah Nuswantoro. Vol. 12 No.1.

[5] Ni Ketut Dewi Ari Jayanti (2014) “Analisa Pengelompokan Konstrasi Program Studi Menggunakan K-Means Clustering" Ed. Konferensi Nasional Sistem Informasi.

[6] Rendi Handoyo, et.al (2014) "Perbandingan metode clustering menggunakan metode Single Linkage dan K-means pada Pengelompokan Dokumen" Ed. Issn Vol. 15.

[7] Rima Dias Ramadhani (2013) "Data Mining Menggunakan Algoritma K-means Clustering Untuk menentukan Strategi Promosi Univeristas Dian Nuswantoro" Ed. Jurnal. 
[8] Tacbir Hendro Pudjiantoro, et.al(2011) "Penerapan Data Mining Untuk Menganalisa Kemungkinan Pengunduran Diri Calon Mahasiswa Baru" Ed. Konferensi Nasional Sistem dan Informatika.
[9] Yudi Wibisono (2011) "Perbandingan Partition Around Medoids (PAM) dan KMeans Clustering Untuk Tweets” Ed. Jurnal Knsi. 